УДК 004.02:681.5

DOI https://doi.org/10.32838/2663-5941/2021.4/20

\title{
Петросян А.P.
}

Державний університет «Житомирська політехніка»

\section{Петросян Р.В.}

Державний університет «Житомирська політехніка»

\section{Підтиченко О.В.}

Державний університет «Житомирська політехніка»

\section{ОПТИМІЗАЦІЯ МОДЕЛІ ПІД-РЕГУЛЯТОРА НА БАЗІ ЦИФРОВОГО ФІЛЬТРУ}

Завдання ефективного управління технологічними процесами, робототехнічними системами, літальними апаратами та іншими технічними засобами залишається актуальним для багатьох галузей промисловості. 3 ццією метою в багатьох сферах техніки використовують ПІД-регулятори.

Налаштування ПІД-регуляторів може бути здійснено кількома способами, в тому числі параметри регулятора можуть бути отримані в аналітичній формі. Однак більшість иих методів розроблені для аналогового ПІД-регулятора. Модель ичифрового ПІД-регулятора не повністю відповідає аналоговому ПІД-регулятору, тому методи розрахунку параметрів аналогового ПІД-регулятора не завжди можуть бути використані. Основна похибка спостерігається у диференціюючій складовій частині на верхніх частотах, тобто там, де він повинен виконувати свою функиію.

Впровадження сучасної елементної бази вносить корективи до всіх сфер науки і техніки (в тому числі й до алгоритмів систем управління). Не став винятком і ПІД-регулятор. В основу нової моделі регулятора покладено методи ичфрової фільтращії. Як фільтруючий пристрій запропоновано використати КIX-фільтр із лінійною фазою. Це дало змогу досить точно апроксимувати диферениіюючий складник. Так, для класичного ичиррового ПІД-регулятора введенням одного коефіиієнта вдалося знизити відносну похибку АЧХ вдвічі.

Для оптимізаиії коефіцієнтів фільтру використано метод наймениих квадратів. Результати моделювання були проведені з використанням мови програмування Руthоп. Були проаналізовані параметри ПІДрегулятора для всіх цифрових фільтрів до 15 порядку (до 8 незалежних коефіиієнтів). Аналіз показав, що для більшості завдань систем управління досить використати фільтри з 4-6 незалежними коефіиієнтами.

Перспективи подальших досліджень полягають у тестуванні запропонованого методу на більш широкому спектрі завдань, пошуку інших методів оптимізаиії, дослідженні ефектів кінщевої розрядності, аналізі структури ПІД-регулятора.

Ключові слова: ПІД-регулятор, иифровий фільтр, метод найменших квадратів.

Постановка проблеми. Завдання ефективного управління технологічними процесами, робототехнічними системами, літальними апаратами та іншими технічними засобами залишається актуальним для багатьох галузей промисловості. 3 цією метою в багатьох сферах техніки використовують ПІД-регулятори [1].

В останні роки роль і значення обчислювальної техніки в житті сучасного суспільства різко збільшилися і постійно продовжують рости, тому сучасні технічні засоби реалізуються здебільшого на базі мікропроцесорів і мікроконтролерів, а більшість рішень задач адаптують для роботи в цифрових пристроях.

Налаштування ПІД-регуляторів може бути здійснено кількома способами, в тому числі пара- метри регулятора можуть бути отримані в аналітичній формі [1-4]. Однак більшість цих методів розроблені для аналогового ПІД-регулятора і не підходять для цифрового, тому що його модель не зовсім точно відповідає ПІД-регулятору, i, відповідно, оптимізація моделі цифрового ПІД-регулятора є актуальним завданням.

Аналіз останніх досліджень i публікацій. У загальному вигляді система управління будьяким об'єктом має вигляд, наведений на рис. 1.

Алгоритм управління об'єктом у часовій області реалізується відповідно до виразу (1) [1]:

$$
u(t)=K_{p} e(t)+K_{i} \int_{0}^{t} e(t) d t+K_{d} \frac{d e(t)}{d t},
$$

де $K_{p}, K_{i}, K_{d}$ - коефіцієнти ПІД-регулятора. 


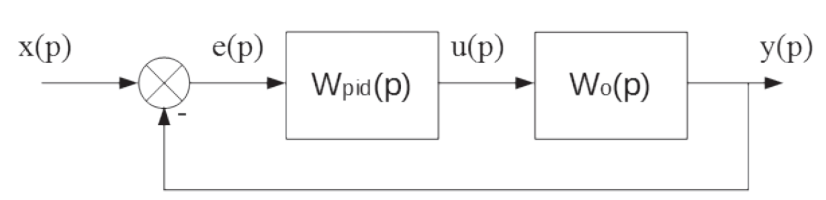

Рис. 1. Система управління об'єктом: $W_{\text {pid }}(p)$ - передаточна функція ПІД-регулятора, $W_{o}(p)$ - передаточна функція об''єкта управління, $x(p), y(p), e(p), u(p)$ - вхідна дія, вихідний сигнал, сигнал неузгодженості, керуючий сигнал відповідно

ПІД-регулятор включає три складові частини: пропорційну, інтегруючу та диференціюючу. Пропорційна складова частина формує керуючий сигнал, який протидіє відхиленню (неузгодженості) вихідного сигналу від заданого значення. Чим більше неузгодженість, тим більший вплив на об'єкт управління. Якщо вихідний сигнал дорівнює заданому значенню, то сигнал неузгодженості дорівнює нулю, а отже, керуючий вплив пропорційної складової частини дорівнює нулю. Інтегруюча складова частина використовується для усунення статичної похибки. Диференціююча складова частина враховує швидкість зміни вихідного сигналу, що дозволяє отримати більш якісне управління об'єктом за рахунок прогнозування вихідної величини сигналу [1].

Існує кілька груп оцінки показників якості управління об'єктом: прямі, кореневі, частотні, інтегральні. На практиці найбільше застосування знайшли прямі показники якості. Це пов'язано 3 тим, що прямі показники якості управління об'єктом визначаються безпосередньо за перехідною характеристикою. Вибір показників якості регулювання залежить від задачі, в якій використовується ПІД-регулятор.

Для забезпечення необхідних показників якості регулювання необхідно розрахувати коефіцієнти ПІД-регулятора. Один із перших методів розрахунку параметрів ПІД-регуляторів запропонували Ziegler J. i Nichols N. [2, 3]. Ця методика дає не дуже гарні результати, проте дуже проста, тому досі часто використовується на практиці. Після розрахунку параметрів регулятора потрібно вручну підлаштувати їх для поліпшення якості регулювання.

У роботі [3] також розглянуто інші методи розрахунку параметрів ПІД-регуляторів, а саме: Чину-Хронеса-Ресвіка, Куна. Широко застосовуються релейні методи [4].

Якщо розглянуті методи розроблені відносно давно, то нижчевикладені методи - досить недавно.
У роботі $[5,6]$ розглянуті методи оптимізації параметрів ПІД-регулятора з використанням генетичного алгоритму. У цих роботах аналізується вибір: фітнес-функції, основних операторів генетичного алгоритму, показників якості.

У роботі [7] розглянуто можливість застосування нейронних мереж для оптимізації коефіцієнтів ПІД-регулятора. Основний акцент у статті робиться на аналізі стабільності таких систем.

Багато робіт пов'язані 3 визначенням оптимальних параметрів ПІД-регулятора під конкретні об'єкти управління [6-8].

Велика кількість робіт пов'язана з розробленням цифрового ПІД-регулятора [9-13]. Однак усі наведені статті можна розбити на дві групи.

Перша група робіт спирається на вираз (2), наведений в [9-11]:

$$
u(n)=K_{p} e(n)+K_{i d} \sum_{k=0}^{n} e(k)+K_{d d}(e(n)-e(n-1)),
$$

де $T_{k}-$ період дискретизації, $K_{i d}=K_{i} T_{k}$, $K_{d d}=K_{p} / T_{k}$.

Друга група робіт спирається на вираз (3), наведений в $[12,13]$ :

$$
u(n)=u(n-1)+K_{1} e(n)+K_{2} e(n-1)+K_{3} e(n-2),
$$

де $K_{1}=K_{p}+K_{i}+K_{d}, K_{2}=-K_{p}-2 K_{d}, K_{3}=K_{d}$.

Аналіз показав, що вирази (2) і (3) практично ідентичні. Основна відмінність між ними полягає в тому, що вираз (2) дозволяє визначити коефіцієнти цифрового ПІД-регулятора по аналоговому прототипу. За виразом (3) коефіцієнти $K_{1}, K_{2}, K_{3}$ необхідно підбирати при ручному налаштуванні системи управління, тому що в них не врахована частота дискретизації.

3 урахуванням вищесказаного випливає, що цифровий та аналоговий ПІД-регулятори не розглядаються як різні сутності, тому методи розрахунку коефіцієнтів регулятора розглядаються незалежно від того, цифровий він чи аналоговий. Однак, як показав аналіз, існує як мінімум дві реалізації цифрового ПІД-регулятора, тому методи розрахунку повинні враховувати його структуру. Крім того, як далі буде показано, цифровий регулятор не $є$ повним аналогом класичного аналогового ПІД-регулятора. Таким чином, задача оптимізації моделі цифрового ПІД-регулятора $є$ актуальною.

Постановка завдання. Метою роботи $є$ уточнення моделі цифрового ПІД-регулятора за рахунок використання цифрового фільтру.

Для досягнення поставленої мети у роботі потрібно вирішити такі завдання: провести аналіз цифрових фільтрів; запропонувати тип фільтру для ПІД-регулятора; вибрати фітнес-функцію 
для оптимізації коефіцієнтів фільтру; розрахувати коефіцієнти фільтру для моделі ПІД-регулятора; зробити висновки з отриманих результатів.

Виклад основного матеріалу дослідження. Виконаємо перехід від часової області в частотну область представлення ПІД-регулятора. Для цього необхідно виконати перетворення Лапласа для виразу (1), а потім виконати заміну оператора Лапласа $p=j \omega$. В результаті отримаємо вираз для частотної характеристики аналогового ПІДрегулятора (4):

$$
W_{A}(\omega)=K_{p}-K_{i} \frac{j}{\omega}+j K_{d} \omega
$$

де $\omega$ - кругова частота.

Розглянемо амплітудно-частотну характеристику (АЧХ) регулятора при $K_{p}=10, K_{i}=1, K_{d}=1$ (рис. 2).

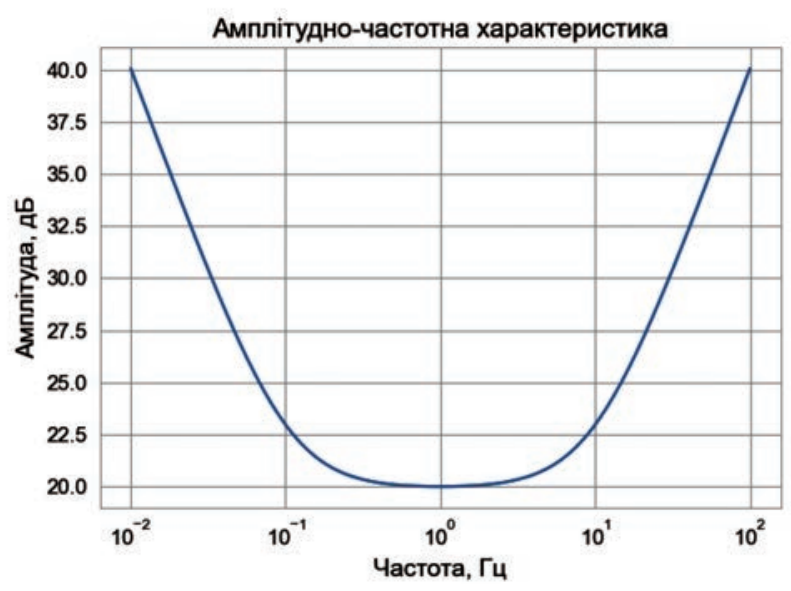

Рис. 2. Зовнішній вигляд АЧХ ПІД-регулятора

АЧХ аналогового ПІД-регулятора показує, що в області нижніх частот впливає інтегруюча складова частина, а в області верхніх частот - диференціююча.

А тепер порівняємо АЧХ диференціюючих складових частин аналогового і цифрового ПІДрегуляторів.

Спочатку запишемо АЧХ диференціюючої складової аналогового ПІД-регулятора. 3 формули (4) видно, що його АЧХ визначається виразом (5):

$$
D_{A}(\omega)=K_{d} \omega .
$$

Якщо виконати аналогічні перетворення, то можемо записати АЧХ диференціюючої складової частини цифрового ПІД-регулятора (6):

$$
D_{L}(\omega)=2 K_{d d} \sin \left(\frac{\omega T_{k}}{2}\right) .
$$

На рис. 3 показані АЧХ обох регуляторів. Для зручності порівняння частоти нормалізовані (частота дискретизації прийнята рівною одиниці), а коефіцієнти прийняті рівними $K_{d}=K_{d d}=1$.
Очевидно, що АЧХ диференціюючих складових частин аналогового i цифрового ПІДрегуляторів не збігаються. На рис. 4 показана відносна похибка. Як видно з рисунка, максимальна похибка становить понад $35 \%$.

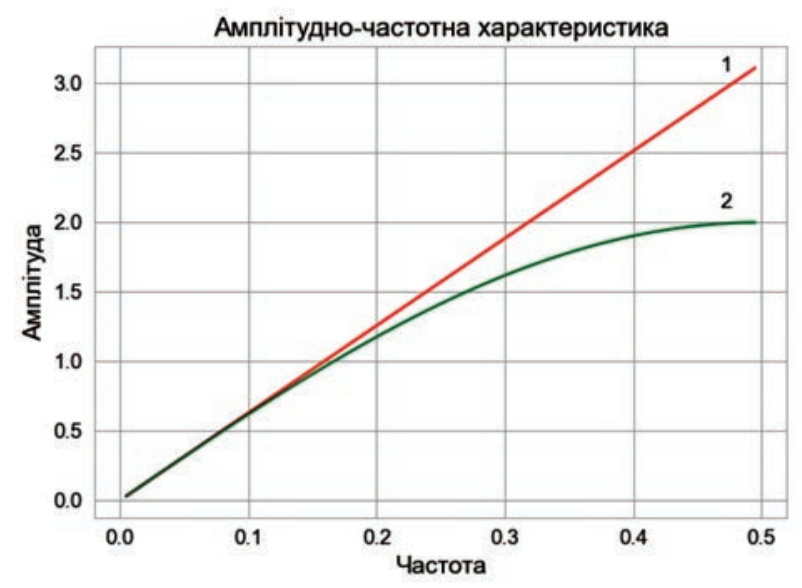

Рис. 3. АЧХ диференціюючих складових частин ПІД-регуляторів: 1 - аналогового; 2 - цифрового

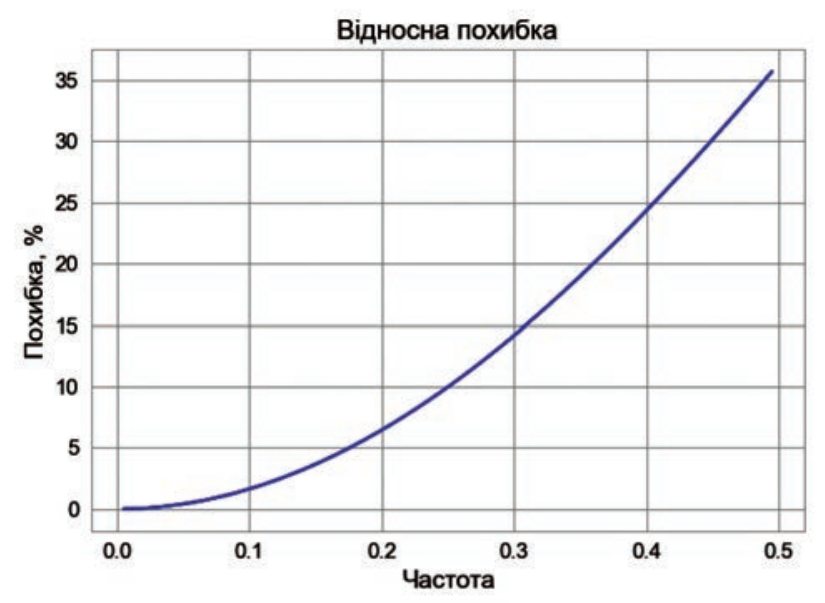

Рис. 4. Відносна похибка диференціюючої складової частини АЧХ цифрового ПІД-регулятора

Для усунення цього недоліку необхідно задатися новою моделлю ПІД-регулятора. Одним із варіантів $€$ використання методів цифрової обробки, а саме використання цифрового фільтра.

Фільтрація - найбільш поширена задача цифрової обробки, яка реалізується з використанням цифрових фільтрів: фільтри 3 кінцевою імпульсною характеристикою (КІХ-фільтри); фільтри з нескінченною імпульсною характеристикою (БІХ-фільтри).

До основних операцій фільтрації інформації відносяться: зменшення шуму, операції згладжування, прогнозування, диференціювання, а також розділення сигналів тощо [14].

У загальному випадку цифровий нерекурсивний фільтр описується таким виразом (7): 


$$
y(n)=\sum_{k=0}^{K-1} h(k) \cdot x(n-k),
$$

де $h(k)$ - коефіцієнти фільтра (імпульсна характеристика).

АЧХ такого фільтра буде мати такий вигляд (8):

$$
H(\omega)=\sum_{k=0}^{K-1} h(k) \cdot e^{-j \omega n} .
$$

У багатьох додатках цифрової обробки сигналів найкраще використовувати КІХ-фільтри, тому що вони мають такі переваги, як:

- групова затримка фільтра постійна (КIXфільтри з лінійною фазою);

- КІХ-фільтри завжди стійкі.

Для того, щоб КІХ-фільтр був із лінійною фазою, необхідно, щоб імпульсна характеристика була симетричною або антисиметричною. В цьому разі можливо чотири типи КIX-фільтрів [14]. Фільтри III i IV типів мають уявну частину частотної характеристики, тому можуть бути використані в ролі диференціюючої складової частини. Однак фільтр III типу не завжди може застосовуватися як такий. Причина в тому, що значення коефіцієнта передачі на максимальній частоті дорівнюватиме нулю $H\left(\omega_{\max }\right)=0$ незалежно від коефіцієнтів фільтра (7). Такий фільтр може використовуватися як диференціюючий тільки на початковій ділянці. Оскільки нам необхідно використовувати весь діапазон, то для нашої задачі кращим рішенням буде скористатися фільтром IV типу.

3 виразу (7) випливає, що диференціююча складова частина для цифрового ПІД-регулятора може бути представлена у вигляді виразу (9):

$$
y(n)=\sum_{l=0}^{L-1} h(l) \cdot(x(n-l)-x(n+l-2 L+1)),
$$

де $L-$ кількість незалежних коефіцієнтів.

У цьому разі, з огляду на (2), алгоритм реалізації цифрового ПІД-регулятора буде описуватися виразом (10):

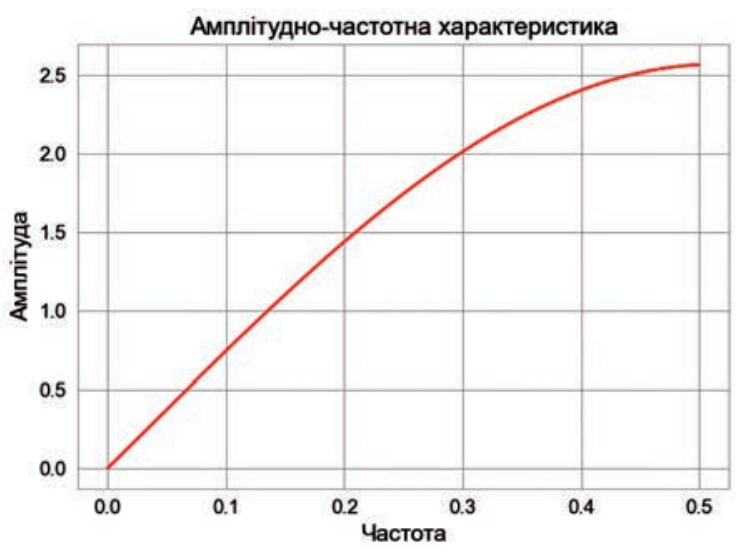

a

$$
\begin{aligned}
& u(n)=K_{p} e(n)+K_{i d} \sum_{k=0}^{n} e(k)+ \\
& +K_{d d} \sum_{l=0}^{L-1} h(l) \cdot(e(n-l)-e(n+l-2 L+1)) .
\end{aligned}
$$

Надалі для простоти будемо називати його ППІД. Для зменшення обчислювальних витрат вираз (10) можна записати в такому вигляді (11):

$$
\begin{aligned}
& u(n)=K_{p} e(n)+I(n)+ \\
& +K_{d d} \sum_{l=0}^{L-1} h(l) \cdot(e(n-l)-e(n+l-2 L+1)) .
\end{aligned}
$$

де $I(n)=I(n-1)+K_{i d} e(n)-$ інтегруюча складова частина.

Для отримання остаточної моделі ППІДрегулятора необхідно визначити коефіцієнти фільтра $h(l)$, де $l=1,2,3, \ldots, L-1$. Для синтезу фільтра (9) необхідна фітнес-функція. Синтез фільтра буде виконуватися з використанням методу найменших квадратів (12):

$$
e=\sqrt{\int_{0}^{\pi} W(\omega)(H(\omega)-\widehat{H}(\omega))^{2} d \omega} \rightarrow \min ,
$$

де $H(\omega), \widehat{H}(\omega)$ - АЧХ апроксимованого й апроксимуючого фільтрів відповідно; $W(\omega)=a \omega+b-$ вагова функція; $a, b$ - коефіцієнти вагової функції.

Як АЧХ апроксимованого фільтра буде виступати АЧХ диференціюючої складової частини аналогового ПІД-фільтра (5) при $K_{d}=1$ (рис. 3, графік 1).

Для обчислення цифрового фільтра була реалізована програма на мові програмування Python. На рис. 5 наведені результати синтезу диференціюючої складової частини ППІД-регулятора. У табл. 1 наведені розраховані коефіцієнти фільтрів різного порядку, а також вказана похибка апроксимації диференціюючої складової частини ППІД-регулятора.

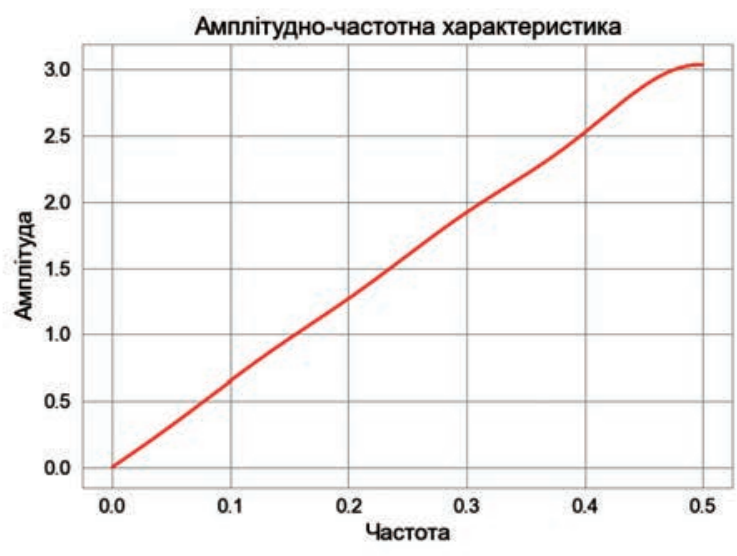

$\mathrm{b}$

Рис. 5. АЧХ диференціюючої складової частини ППІД-регулятора: а) $L=1$; b) $L=6$ 


\begin{tabular}{|l|c|c|}
\hline \multicolumn{1}{|c|}{ Коефіціснти КІХ-фільтра для розробленої моделі цифрового ПІД-регулятора } \\
\hline \multicolumn{1}{|c|}{$\boldsymbol{h}(\boldsymbol{l})$} & \multicolumn{1}{c}{ Таблиця 1} \\
\hline 1 & \multicolumn{1}{|c|}{1.27850625} & 18.61 \\
\hline 2 & $-0.13897425,1.27275787$ & 10.13 \\
\hline 3 & $0.05145017,-0.14162243,1.27340767$ & 6.64 \\
\hline 4 & $-0.02575393,0.05096566,-0.14150234,1.27328925$ & 5.05 \\
\hline 5 & $0.01589056,-0.02605942,0.05100875,-0.14154174,1.27331104$ & 4.01 \\
\hline 6 & $-0.01048371,0.01575979,-0.02602363,0.05097624,-0.14151715,1.27328708$ & 3.36 \\
\hline 7 & $0.00762269,-0.01057292,0.0157707,-0.02603239,0.05097792$, & 2.87 \\
\hline 8 & $-0.14151841,1.27328701$ & 2 \\
& $0.05096753,-0.1415089,1.27327763$ & 2.51 \\
\hline
\end{tabular}

Якщо порівняти запропоновану модель ППІДрегулятора при $\mathrm{L}=1$ з класичним цифровим ПІДрегулятором (2), то можна помітити, що вирази відрізняються тільки множником $h(0)$ (табл. 1). Однак завдяки йому похибку вдалося знизити майже вдвічі. Також із табл. 1 видно, що краще використовувати цифровий фільтр 34 " L" 6 , тому що подальше збільшення кількості коефіцієнтів не приводить до істотного збільшення точності.

Висновки. У роботі проведено розроблення моделі цифрового ПІД-регулятора 3 використанням цифрового фільтру. Основна похибка спостерігається у диференціюючої складової частини цифрового ПІД-регулятора.
У результаті аналізу цифрових фільтрів було запропоновано використати нерекурсивний цифровий фільтр із лінійною фазою. Існує чотири типи таких фільтрів. Для уточнення моделі цифрового ПІД-регулятора було запропоновано використати IV тип фільтру.

Для оптимізації коефіцієнтів фільтру вибрано метод найменших квадратів. Результати розрахунку коефіцієнтів фільтру показали, що при кількості коефіцієнтів, рівній одному (як у класичній моделі цифрового ПІД-регулятора), відносна похибка зменшується майже вдвічі. Однак використання кількості коефіцієнтів більше шести недоцільно.

\section{Список літератури:}

1. Самотокін Б.Б. Лекції з теорії автоматичного керування: навч. посібник. Житомир: ЖІТІ, 2001. 508 с.

2. Ziegler J.G., Nichols N.B. Optimum settings for automatic controllers. Transactions of the ASME, 1942. Vol. 64. P. 759-768.

3. Миллер Ю.В., Саблина Г.В. Расчёт параметров ПИД-регулятора. Автоматика и программная инженерия. 2020. № 1. С. 148-153.

4. Åström K.J.; Hägglund T. Automatic Tuning of Simple Regulators. IFAC Proceedings volumes. 1984. № 17(2). P. 1867-1872. DOI: https://doi.org/10.1016/S1474-6670(17)61248-5.

5. Mirzal A., Yoshii S., Furukawa M. PID Parameters optimization by using genetic algorithm. URL: https://arxiv.org/ftp/arxiv/papers/1204/1204.0885.pdf. (дата звернення: 10.05.2021).

6. Jayachitra A., Vinodha R. Genetic algorithm based PID controller tuning approach for continuous stirred tank reactor. Advances in Artificial Intelligence. 2014. DOI: https://doi.org/10.1155/2014/791230.

7. Kadua C.B., Patil C.Y.. Design and implementation of stable PID controller for interacting levelcontrol system. Procedia Computer Science. Volume 79. 2016. P. 737-746. DOI: https://doi.org/10.1016/j. procs.2016.03.097.

8. Кузьменко М.Ю., Егоров А.П. Математическая модель системы управления тепловым агрегатом с типовыми промышленными регуляторами. Збірник наукових праць Національного гірничого університету. 2011. № 36(1). С. 106-110.

9. Franklin G.F., Powell J.D., Workman M.L. Digital control of dynamic systems, 2nd ed. Addison-Wesley, 1990. $841 \mathrm{p}$.

10. Baikar P.M. Design of PID controller based information collecting robot in agricultural field. International Journal of Advanced Research in Electrical, Electronics and Instrumentation Engineering. Vol. 3, issue 8. 2014. DOI: https://doi.org/10.15662/ijareeie.2014.0308016.

11. Hou D. PID control on PIC16F161X by using a PID Peripheral. Microchip Technology Inc. TB3136. 2015. URL: http://ww1.microchip.com/downloads/en/AppNotes/90003136A.pdf. (дата звернення: 10.05.2021). 
12. Maghsadhagh A. Implementation of PID controller by microcontroller of PIC (18 Series) and controlling the height of liquid in sources. Adv. Robot Autom. Vol. 5. 2016. P. 156-159. DOI: https://doi. org/10.4172/2168-9695.1000156.

13. Masade S., Parmar S., Bhanushali A., Speed control for brushless DC motors using PID algorithm. Einfochips. URL: https://www.einfochips.com/images/partners/xilinx/Speed-Control-for-Brushless-DC-MotorUsing-PID-Algorithm.pdf. (дата звернення: 10.05.2021).

14. Proakis J., Manolakis D. Digital Signal Processing, 4th Edition. London: Pearson, 2013. 1019 p.

\section{Petrosian A.R., Petrosian R.V., Pidtychenko O.V. OPTIMIZATION OF THE PID CONTROLLER MODEL BASED ON A DIGITAL FILTER}

The task of efficient management of technological processes, robotic systems, aircraft and other technical means remains relevant to many industries. For this purpose, in many areas of technology, PID controllers are used.

Configuring PID controllers can be accomplished in several ways, including the regulator parameters can be obtained in an analytical form. However, most of these methods are designed for an analog PID controller. The digital PID controller model does not fully correspond to the analog PID controller, so methods for calculating the parameters of an analog PID controller can not always be used. The main error is observed in the differentiation component in the upper frequencies, that is, where it must perform its function.

Implementation of a modern element base makes adjustments to all spheres of science and technology (including algorithms of control systems). Did not make an exception and a PID controller. The basis of a new model of the regulator is the methods of digital filtration. As a filter device, a FIR filter with a linear phase is used. This allowed accurately to approximate a differentiating component. Thus, for a classic digital PID controller, the introduction of one coefficient managed to reduce the relative error of the amplitude response twice.

The least squares method is used to optimize the filter coefficients. The results of modeling were conducted using Python programming language. The parameters of the PID controller for all digital filters to 15 order (up to 8 independent coefficients) were analyzed. The analysis showed that for most of the tasks of control systems, it is enough to use filters with 4-6 independent coefficients.

Prospects for further research are testing the proposed method on a broader spectrum of tasks, the search for other methods of optimization, studying the effects of finite bit depth, analysis of the structure of the PID controller.

Key words: PID controller, digital filter, least squares method. 